\title{
Considerações acerca dos refugiados ambientais
}

\author{
Considerations about the environmental refugees
}

Paula Oliveira Maciel $^{1}$

1 Bacharel em Direito pela Escola Superior Dom Helder Câmara. E-mail: paulinhaoliveiramaciel@gmail.com

\begin{abstract}
RESUMO: O Direito Internacional Humanitário, tem como função, a proteção da pessoa, assegurado ao indivíduo condições mínimas de existência. Tem-se, também, essa preocupação com os refugiados, pessoas perseguidas em razão de nacionalidade, raça, grupo social, grupo religioso ou opinião política. Entretanto, não abarca aqueles que não podem viver em seu país, em razão de catástrofes ambientais. Não há dispositivo legal que regule essa situação. $\mathrm{O}$ artigo tem objetivo analisar os refugiados ambientais, usando o método dedutivo, para analisar se existe a possibilidade de proteção a essas pessoas, utilizando instituto do refúgio e as garantias do Direito Internacional e Direito Humanitário.

Palavras-chave: Direito Internacional. Direitos humanos. Meio Ambiente. Refugiados Ambientais.
\end{abstract}

\begin{abstract}
The International humanitarian law has the function of protecting the person, ensuring the individual minimum conditions of existence. There is also concern for refugees, people persecuted on grounds of nationality, race, social group, religious group or political opinion. However, it does not cover those who can not live in their country because of environmental disasters. There is no legal provision to regulate this situation. The article aims to analyze environmental refugees, using the deductive method, to analyze if there is a possibility of protection to these people, using the refuge institute and the guarantees of International Law and Humanitarian Law.
\end{abstract}

Keywords: International Law. Human rights. Environment. Environmental refugees.

Sumário: Introdução - 1 A questão ambiental - 2 Considerações acerca dos refugiados e refugiados ambientais - Considerações Finais - Referências

\section{INTRODUÇÃO}

A movimentação de pessoas em torno do globo pode se dar por diferentes motivos, podendo ser por fins turísticos ou em busca de condições melhores de vida. Assim, alguns desses movimentos migratórios, são abarcados pelo Direito Internacional, por meio dos institutos do Asilo e Refúgio. Preocupada com essa questão migratória também, a Organização das Nações Unidas (ONU), em 1951, adotou a Convenção Relativa ao Estatuto dos Refugia- 
dos, que passou a vigorar em 1954.

Segundo o Estatuto do Refugiado, em seu artigo 1ㅇ, qualquer pessoa que temendo ser perseguida por motivos de raça, religião, nacionalidade, grupo social ou opiniões políticas, tem o direito de procurar refúgio em outro país. Ocorre que, com o mundo cada vez mais globalizado, a produção e consumo sempre em escalas elevadas, a extração dos recursos naturais cada dia mais ostensiva, o meio ambiente passa a dar sinais, cada vez mais evidentes, de que não conseguirá acompanhar esse ritmo. As mudanças climáticas, o aumento no nível dos oceanos, processos de desertificação, inundações, furacões, são só alguns exemplos que comprovam essa triste realidade do planeta.

Além desses problemas já serem terríveis em si, trazem consigo consequências ainda piores, os refugiados ambientais. Pessoas que em virtude dessas mudanças climáticas, perdem o local onde habitam. O Estatuto dos Refugiados é bem taxativo, quando elenca as hipóteses em que pessoas podem procurar refúgio, o objetivo desse artigo é, então, analisar, com auxílio do método indutivo, se há possibilidade de aceitação de refugiados ambientais, com base no Estatuto. Diante desse objetivo, o artigo perpassa a questão ambiental e analisa o instituto do refúgio, tentando oferecer soluções para que essas pessoas possam gozar de proteção e ter um mínimo existencial.

\section{A QUESTÃO AMBIENTAL}

Há algum tempo o planeta Terra vem demonstrando sinais de que precisa de cuidados e proteção. Mudanças climáticas, aumento dos níveis dos oceanos, elevadas temperaturas, processos de desertificação, tornados, furacões, tsunamis e enchentes são apenas alguns exemplos dos problemas que planeta vem enfrentando.

Com o capitalismo a todo vapor, o mundo cada vez mais globalizado, a produção e consumo sempre em escalas elevadas, o enaltecimento do ter pelo ser, fazem com que a balança sempre penda para o lado do ganho econômico, em detrimento do meio ambiente. A esse respeito Padilha afirma que

[...] a apropriação privada de bens e na acumulação de riquezas, redimensiona a extensão da exploração da natureza e maximiza a agressividade dos mecanismos de depredação, o comportamento humano, [...] passa a se tornar altamente nocivo ao meio ambiente. (PADILHA, 2010, p. 2).

Surge então um impasse, como conciliar o desenvolvimento econômico, de forma a não findar os recursos naturais? De acordo com estudo divulgado pela ONU, se não houver mudanças, em 2050, a humanidade pode consumir anualmente 120 bilhões de toneladas de recursos naturais. Essa situação demonstra claramente que um novo caminho deve ser tomado e se torna imprescindível a busca por um desenvolvimento pautado na sustentabilidade.

A partir da década de 1960, inicia-se uma percepção de que a questão da proteção ambiental é de extrema importância para manutenção da vida humana na terra, de acordo 
com Padilha, essa percepção advém da

[...] denúncia da dimensão da poluição industrial provocada a partir da Revolução Industrial, e dos perigos para a saúde humana e ambiental, da acumulação dos resíduos de substancias nocivas e tóxicas, principalmente nos países desenvolvidos (PADILHA, 2010, p. 1).

Em 1972, após o início dessa discussão ambiental, a Suécia, propõe à ONU, a realização de uma conferência, para tratar dos problemas ambientais. Então, em junho de 1972, na cidade de Estocolmo, realiza-se a Conferência das Nações Unidas Sobre o Meio Ambiente Humano, contando com a participação de 113 países, 250 organizações não-governamentais e organismos da ONU. A partir daí criou-se também, o Programa das Nações Unidas para o Meio Ambiente (PNUMA).

De acordo com Milaré (2009, p. 1191), a conferência é "também conhecida como Declaração de Estocolmo, ela contém 26 princípios referentes a comportamentos e responsabilidades, que se destinam a nortear os processos decisórios de relevância para a questão ambiental" Enquanto que para Padilha

[...] a realização da conferência tornou a década de 1970 um marco no reconhecimento da relevância internacional da questão ambiental, pois, pela primeira vez, países desenvolvidos e em via de desenvolvimento se reuniram para discutir os impactos no meio ambiente, decorrentes da ação humana. (PADILHA, 2010, p. 48).

Assim, observa-se a importância da Conferência para as questões ambientais. Foi por meio dela que, pela primeira vez, reconheceu-se a indissociabilidade do ser humano com o meio ambiente, assim como sua responsabilidade sobre as mudanças sofridas pelo planeta.

Após a Conferência em Estocolmo, outras conferências de temática ambiental, foram acontecendo com o passar dos anos. Podendo-se destacar a Convenção-Quadro Clima das Nações Unidas Sobre Mudança do Clima, ocorrida na RIO/92. Assinaram esta convenção 154 Estados e a comunidade Europeia e ficou estabelecido normas para redução da emissão dos gases de efeito estufa, principais causadores do aumento da temperatura da terra.

A convenção entrou em vigor em março de 1994, contando com a participação de 182 países e como consequência da Convenção-Quadro, em dezembro de 1997, no Japão, é adotado o Protocolo de Quioto, que de acordo com Padilha é

[...] um acordo complementar à Convenção-Quadro Sobre Mudança do Clima, veio regulamentá-la por meio de regras especificas para efetivação dos seus objetivos, estipulando compromissos concretos para a redução dos gases de efeito estuda, impondo metas obrigatórias de redução para os países desenvolvidos (chamados países do Anexo I), tendo definido como objetivo a ser alcançado pelos países signatários, entre os anos de 2008 e 2012, a redução até o patamar de $5 \%$ inferior às emissões realizadas no ano de 1990. (PADILHA, 2010, p. 88).

Dessa forma, percebe-se que a questão ambiental internacional não é tão antiga como

Planeta Amazônia: Revista Internacional de Direito Ambiental e Políticas Públicas 
outras questões sociais, contudo passos importantes já foram dados e apesar de caminhar a passos lentos, a trajetória já fora iniciada. Ainda, é necessário mais soluções e diálogos. Ou seja, há muito a ser feito, mas é importante ressaltar que o processo de informação, isto é, a necessidade da proteção ambiental é urgente.

\section{CONSIDERAÇÕES ACERCA DOS REFUGIADOS E REFUGIADOS AMBIENTAIS}

O instituto do asilo existe há vários anos, desde do Egito Antigo, passando pela Grécia, Roma, Idade Média e Moderna. Para Guimarães (2010, p. 108) o termo Asilo é um “substantivo masculino, lugar que recolhe pessoas carentes, ou que oferece abrigo, proteção, repouso, temporária ou permanente". Enquanto que para Pereira

[...] o direito de asilo é um direito natural dos indivíduos perseguidos, fundamentado no direito à proteção. Esse direito encontra amparo em um dever, em uma obrigação correlata e de responsabilidade dos Estados que é o dever de auxílio humanitário internacional (Pereira, 2009, p. 49).

Assim toda e qualquer pessoa, que se sinta perseguida, tem direito à proteção. Para Carvalho asilo é a acolhida presta "ao perseguido provindo de jurisdição externa, cujos direitos fundamentais sofrem ameaça grave real ou presumida. O asilo para ser considerado depende de condições estabelecidas pelo Direito Internacional" (Carvalho, 2000, p. 1).

Com relação ao termo refúgio Carvalho (2000, p. 4), explica “[...] é quase sempre o único caminho que se abre aos desgraçados que se abalam em busca de amparo, de socorro, de sobrevivência e também de justiça. Trata-se de um resguardo das graves violações de direito humanitário internacional"

Ora, se os dois institutos têm por objetivo a proteção de indivíduos perseguidos, no que se diferem? Para Pereira (2009), a primeira distinção seria a histórica, já que o asilo existe desde a Antiguidade e o refúgio após o fim da I Guerra Mundial. Outra diferença seria o caráter regional do asilo, ao passo que o refúgio é assegurado internacionalmente, já que tem por base cinco motivos que se baseiam no temor da perseguição, quais sejam: raça, religião, opinião política, pertencimento a um determinado grupo social e nacionalidade.

Assim, as hipóteses em que se definem o refúgio são claras, delimitadas e objetivas, já a hipótese de asilo é discricionária, afinal o Estado acolhedor irá fazer um juízo de valor, se aquele indivíduo está ou não sofrendo perseguição política, podendo ou não lhe conceder asilo político. Para caracterização do refúgio é imprescindível a extraterritorialidade, para o asilo nem sempre. A concessão de asilo seria um direito constitutivo e o status de refugiado seria declaratório, decorrente dessa diferenciação, como pode ser observado na explicação a seguir

Assim sendo, por ser uma decisão discricionária do Estado a concessão ou não de asilo, desta não decorrem obrigações internacionais para ele, nem mesmo a necessidade de formulação de políticas públicas que visem integrar o asilado político a seu novo local de moradia. Ao contrário, a partir do reconhecimento do status de refugiado, 
o Estado de acolhida tem a obrigação de integrá-lo à comunidade e, igualmente, decorrem para o país obrigações internacionais. Contudo, cláusulas de exclusão e de cessação do refúgio existem, não sendo o mesmo verdade para o direito de asilo. Finalmente, outra marcada distinção reside na existência do ACNUR, órgão especifico de fiscalização da prática do refúgio, pois para o resguardo do instituto do asilo, não existe órgão correlato. (PEREIRA, 2009, p. 66)

Assim, é plausível concluir que ambos os institutos possuem respaldo no Direito Internacional dos Direitos Humanos, o Direito Internacional Humanitário e o Direito Internacional dos Refugiados.

De acordo com a ONU (2017a), os direitos humanos são inerentes a todos os seres humanos, independente de raça, etnia, sexo, nacionalidade, idioma, religião ou qualquer outra condição. O Direito Internacional dos Direitos Humanos estabelece as diretrizes que os governos devem seguir ou atos que devem se abster, visando a proteção e promoção dos direitos humanos e as liberdades de grupos ou individuais.

Os Direitos Humanos são normalmente compreendidos como aqueles direitos inerentes ao ser humano. Em consonância a esta afirmação Pereira explica que os ramos do direito internacional

[...] em decorrência do propósito e objetivo específico que possuem, isto é, a finalidade precípua de proteção da pessoa humana em toda e qualquer circunstância, tendo-a, consequentemente, como destinatário final de suas normas processuais e substantivas. (PEREIRA, 2009, p. 14).

Ainda segundo a ONU (2017b), os direitos humanos são fundados sobre o respeito e pela dignidade de cada indivíduo; os direitos humanos são universais, de forma que toda e qualquer pessoa, independentemente de qualquer coisa é detentora; os direitos humanos são inalienáveis, e ninguém pode ser privado de seus direitos; os direitos humanos são indivisíveis, inter-relacionados e interdependentes, ou seja, não há possibilidade de se respeitar um direito, ferindo outro ou respeitar somente uma parte de um direito. Assim todos os direitos humanos devem ser tratados com igual importância, sendo igualmente essencial respeitar a dignidade e valor de cada pessoa.

Neste sentido é importante lembrar da Declaração Universal Dos Direitos do Humanos, adotada pela Assembleia Geral da ONU, em 10 de dezembro de 1948, um marco que definiu, pela primeira vez, os direitos humanos fundamentais que deveriam ser universalmente protegidos como pode ser observado no trecho a seguir.

Este documento, marco do início da internacionalização da proteção aos direitos humanos no mundo contemporâneo, possui sua origem histórica convergente à da própria criação da ONU, qual seja, o horror e repúdio da humanidade, após o final da I e II Grandes Guerras, às gravíssimas, violentas, genéricas e maciças violações de direitos humanos que, durante a ocorrência destes dois conflitos, foram perpetradas, sobretudo, no território europeu. Neste sentido, a garantia da paz e segurança internacionais, objetivo institucional central da Organização, bem como a sobrevivência 
sadia da raça humana e a preservação e consolidação de seus direitos essenciais, passaram a ter lugar de destaque na agenda internacional, constituindo-se na máxima "direito a ter direitos (PEREIRA, 2009, p. 17).

Sendo, portanto, a proteção da pessoa, o cerne dos Direitos Humanitários, nesse contexto tem-se, também, o Direito Internacional dos Refugiados, que tem por função primária a proteção daqueles que sofrem algum tipo de violação. De acordo com Pereira (2009, p. 34), o Direito Internacional dos Refugiados, que tem como finalidade principal nas relações internacionais "proteger os indivíduos que, por motivos de raça, nacionalidade, opinião, politica, religião ou pertencimento a grupo social, foram forçados a abandonar seus lares para irem viver em uma região do globo que não a sua de costume ou origem".

Assim, seguindo decisão da Assembleia Geral da ONU, em 1950, fora convocada em Genebra, conferência de Plenipotenciários das Nações Unidas, para redigir uma convenção acerca do status de refugiado. Dessa forma, a Convenção das Nações Unidas Sobre Estatuto dos Refugiados, foi adotada em 28 de julho de 1951, passando a vigorar em 22 de abril de 1954. Nesse sentido,

A Convenção consolida prévios instrumentos legais internacionais relativos aos refugiados e fornece a mais compreensiva codificação dos direitos dos refugiados a nível internacional. Ela estabelece padrões básicos para o tratamento de refugiados - sem, no entanto, impor limites para que os Estados possam desenvolver esse tratamento. A Convenção deve ser aplicada sem discriminação por raça, religião, sexo e país de origem. Além disso, estabelece cláusulas consideradas essenciais às quais nenhuma objeção deve ser feita. Entre essas cláusulas, incluem-se a definição do termo "refugiado" e o chamado princípio de non-refoulement (não-devolução), o qual define que nenhum país deve expulsar ou "devolver" (refouler) um refugiado, contra a vontade do mesmo, em quaisquer ocasiões, para um território onde ele ou ela sofra perseguição. Ainda, estabelece providências para a disponibilização de documentos, incluindo documentos de viagem específicos para refugiados na forma de um "passaporte" (ONU, 2017c).

Com o passar do tempo, novas situações foram surgindo e viu-se a necessidade de ampliação das proteções aos refugiados, então, em 4 de outubro de 1967, entrou em vigor um protocolo, para suprir essas lacunas. Assim,

A Convenção e o Protocolo são os principais instrumentos internacionais estabelecidos para a proteção dos refugiados e seu conteúdo é altamente reconhecido internacionalmente. A Assembleia Geral tem frequentemente chamado os Estados a ratificar esses instrumentos e incorporá-los à sua legislação interna. A ratificação também tem sido recomendada por várias organizações, tal como o Conselho da União Europeia, a União Africana e a Organização dos Estados Americanos. Em novembro de 2007, o número total de Estados signatários da Convenção era de 144 - o mesmo número de signatários do Protocolo de 1967. O número de Estados signatários de ambos os documentos é de 141. O número de Estados signatários de um ou outro documento é de 147. [...]. De acordo com o seu Estatuto, é de competência do Alto 
Comissariado das Nações Unidas promover instrumentos internacionais para a proteção dos refugiados e supervisionar sua aplicação. Ao ratificar a Convenção e/ou o Protocolo, os Estados signatários aceitam cooperar com o ACNUR no desenvolvimento de suas funções e, em particular, a facilitar a função específica de supervisionar a aplicação das provisões desses instrumentos. (ONU, 2017c).

Dessa forma, a Convenção de 1951 e o Protocolo de 1967, são os dispositivos que asseguram a toda e qualquer pessoa, o direito de procurar refúgio em outro país. Neste rol pode-se incluir, também, a Declaração de Cartagena, de 1984, e a Declaração de Viena, de 1993.

A Declaração de Cartagena, fora adotada em 22 de novembro de 1984, resultante de um encontro entre países da América. Para Pereira (2009, p. 96), a adoção da declaração “[...] elevou a temática dos refugiados a uma concepção ampliada, pautada na observância dos direitos humanos e na concentração multilateral de esforços para construção da paz". Ampliou, também, a definição de refugiado, na terceira cláusula conclusiva, como pode ser observado a seguir.

Deste modo, a definição ou o conceito de refugiado recomendável para sua utilização na região é o que, além de conter os elementos da Convenção de 1951 e do Protocolo de 1967 , considere também como refugiados as pessoas que tenham fugido dos seus países porque a sua vida segurança ou liberdade tenham sido ameaçadas pela violência generalizada, a agressão estrangeira, os conflitos internos, a violação maciça dos direitos humanos ou

Outras circunstâncias que tenham perturbado gravemente a ordem pública. (ONU, 1984.)

Após análises das convenções e acordos internacionais percebe-se que em todos os documentos nenhuma menção é feita aos refugiados ambientais. Frente ao exposto cabe, primeiramente, tentar conceituar corretamente o refugiado ambiental, já que esse migra por questões ambientais, e não por outras razões já explicitadas e necessariamente deve haver uma extraterritorialidade.

Há o que se falar também na questão de nomenclatura, como já mencionado, as hipóteses de refúgio são taxativas, não havendo previsão para questões ambientais. E Ihes faltar o requisito de perseguição ou temor de sê-lo. Logo, não se poderia usar o termo refugiado. Para a ONU

A situação se agrava porque o deslocado ambiental não é considerado tecnicamente como um refugiado. A fundadora da Rede Sul-Americana para as Migrações Ambientais (Resama), Érika Pires Ramos, explica que a Convenção das Nações Unidas sobre o Estatuto dos Refugiados, tratado de 1951 que estabelece as normas para a proteção de refugiados, não prevê causas ambientais para a concessão do refúgio, já que elas não são consideradas como "perseguição" ou outras motivações de segurança previstas no tratado internacional. (ONU, 1984).

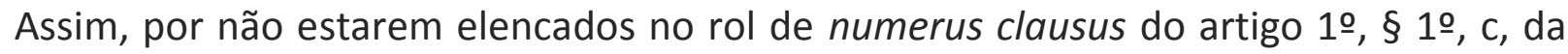


Convenção relativa ao Estatuto dos Refugiados de 1951 e por não apresentarem o temor da perseguição em seu país de origem, cria-se um imenso desafio ao tentar dar proteção à essas pessoas, com base no status de refugiados. Para Pereira, refugiado ambiental seria

\footnotetext{
A pessoa ou grupo de pessoas, que em virtude de mudanças e catástrofes ambientais -naturais ou provocadas pelo homem, permanentes ou temporárias-, tiveram que, forçadamente, abandonar seu local de origem ou residência habitual para encontrar refúgio e abrigo em outra região do globo. (PEREIRA, 2009, p. 117).
}

Este mesmo autor discute que é necessário estar presente e verificado o nexo de causalidade, entre os motivos da perseguição e o deslocamento forçado, em razão de um temor, os refugiados ambientais também deveriam demonstrar esse nexo de causalidade para um pleiteamento futuro de acolhida por parte de um determinado Estado, ou seja o nexo estaria entre o fator ambiental e o deslocamento.

De acordo com a ONU (2017), atualmente, já ocorrem deslocamentos por desastres climáticos e eles não são poucos. Cerca de 25 milhões de pessoas são forçadas a deixar seus países a cada ano devido a problemas ambientais como secas, inundações, tempestades e incêndios florestais. Segundo estimativas do Centro de Monitoramento de Deslocamento Interno, até 2050 esse número chegará a 1 bilhão de pessoas.

\section{CONSIDERAÇÕES FINAIS}

Diante de todo o exposto, pode-se concluir que apesar do avanço na busca pela proteção das pessoas, especialmente em um mundo pós-guerra, essa proteção ainda é ínfima perto dos novos passos rumo ao futuro. Assim, novas situações surgem a cada dia, trazendo a necessidade de que o Direito seja dinâmico e acompanhe esses novos desmembramentos. Nesse contexto, pode-se inferir que os refugiados ambientais são pessoas que, em razão de catástrofes ambientais, são obrigadas a abandonar seus locais de origem ou costume, e procurar um Estado que os acolha, afim de terem condições melhores de vida.

Entretanto, por se tratar de questão relativamente nova, ainda não encontra respaldo nos documentos internacionais. É verdade que há uma busca para que essas pessoas não fiquem lançadas a própria sorte e busca-se que o Direito as socorra, mas como toda mudança, isso se dá de forma gradativa, deixando várias lacunas a serem preenchidas.

Conclui-se, então, que ainda não é possível o enquadramento dos refugiados ambientais, no Estatutos dos Refugiados de 1951, por se tratar de texto taxativo, mas o incentivo para que novos documentos sejam elaborados é grande. Em encontro realizado no Rio de Janeiro pela ONU, em junho de 2017, para discutir os deslocamentos causados por questões climáticas, durante seminário Vozes do Refúgio, os participantes pediram comprometimento com os acordos climáticos e a criação de políticas públicas de proteção para populações em maior situação de vulnerabilidade.

Assim, apesar de todos os limites e barreiras, quanto à aceitação jurídica dos refugiados ambientais, como um conceito amplo e abrangente de refugiado, O Direito Internacional 
e Direito Humanitário, como zeladores do bem-estar, da qualidade de vida e condições mínimas de existência da pessoa humana, devem sempre tentar cumprir com seu papel, buscando sempre o diálogo para a construção de uma sociedade melhor.

\section{REFERÊNCIAS}

CARVALHO, Júlio Marino de. Asilo Político e Direitos Humanos. Rio de Janeiro: Editora Forense, 2000.

ENVOLVERDE JORNALISMO E SUSTENTABILIDADE. Consumo de Recursos Naturais. 2011. Disponível em http://www.envolverde.com.br/consumo-de-recursos-naturais/>. Acesso em 26 de junho de 2017.

MILARÉ, Édis. Direito Ambiental: A Gestão ambiental em Foco. São Paulo: Editora Revista dos Tribunais, 2009.

ORGANIZAÇÃO DAS NAÇÕES UNIDAS. Convenção Relativa ao Estatuto dos Refugiados. 1951. Disponível em: http://www.acnur.org/t3/fileadmin/Documentos/portugues/BDL/Convencao_ relativa_ao_Estatuto_dos_Refugiados.pdf >. Acesso em 10 de julho de 2017.

. Declaração de Cartagena. 1984. Disponível em <http://www.acnur.org/fileadmin/ scripts/doc.php?file=fileadmin/Documentos/portugues/BD_Legal/Instrumentos_Internaciona is/Declaracao_de_Cartagena>. Acesso em 10 de julho de 2017.

O que é a Convenção de 1951?. 2017a. Disponível em <http://www.acnur.org/portu gues/informacao-geral/o-que-e-a-convencao-de-1951/>. Acesso em 09 de julho de 2017.

. ONUBR. 2017b. Disponível em: <https://nacoesunidas.org/mudancas-climaticas-de vem-intensificar-deslocamentos-forcados-dizem-especialistas/>. Acesso em 10 de julho de 2017.

ONUBR. 2017c. Disponível em: http://nacoesunidas.org/direitoshumanos>. Acesso em 08 de julho de 2017.

PADILHA, Norma Sueli. Fundamentos Constitucionais do Direito Ambiental Brasileiro. Rio de Janeiro: Elsevier, 2010.

PEREIRA, Luciana Diniz Durães. O Direito Internacional Dos Refugiados: Análise Crítica do Conceito "Refugiado Ambiental". Belo Horizonte: 2009.

Artigo recebido em 10 de julho de 2017.

Aprovado em 24 de abril de 2018. 